\title{
APRENDIZAGEM COOPERATIVA, DISPOSIÇÃO FÍSICA E METODOLOGIA NO ENSINO JURÍDICO
}

\author{
COOPERATIVE LEARNING, PHYSICAL LAYOUT AND METHODOLOGY IN LAW \\ TEACHING
}

\author{
Emerson Ademir Borges de Oliveira \\ Mestre e Doutor em Direito do Estado pela Universidade de São Paulo. \\ Pós-Doutor em Democracia e Direitos Humanos pela Universidade de Coimbra. \\ Professor permanente e vice-coordenador do Programa de Mestrado e Doutorado em \\ Direito da Universidade de Marília (UNIMAR). Advogado e parecerista. \\ E-mail: emerson@unimar.br \\ Fernanda Mesquita Serva \\ Doutoranda em Educação do Programa de Pós-Graduação em Educação da \\ Universidade Estadual Paulista "Júlio de Mesquita Filho" (UNESP), campus Marília. \\ Pró-reitora de Ação Comunitária da UNIMAR. Mestre em Direito pela UNIMAR. \\ E-mail: fernanda@unimar.br \\ Jefferson Aparecido Dias \\ Doutor em Direitos Humanos e Desenvolvimento pela Universidad \\ Pablo de Olavide, Sevilha, Espanha. Procurador da República em Marília (SP). \\ Professor da Graduação, Mestrado e Doutorado em Direito da UNIMAR. \\ E-mail: jeffersondias@unimar.br \\ Recebido em: 04/09/2018 \\ Aprovado em: 10/01/2019
}

RESUMO: O presente artigo se dedica a analisar como a estrutura física tradicionalmente disponibilizada para as aulas nos Cursos de Direito podem ser modificadas para permitir um aprendizado mais dinâmico e eficiente, preocupado com a formação plena dos alunos e a produção de um conhecimento pluriversitário. O ensino jurídico carece, na atualidade, de disposições informativas que, desde a concepção física, possam influenciar a formação do aluno para fins práticos. Para tanto é necessário repensar nosso modelo de formação jurídica, em um aspecto que passe tanto pelo método de aprendizagem, inserido em um novo contexto espacial, como pela interação das disciplinas jurídicas com aspectos comunitários. Com base nestes modelos, busca-se apresentar um modelo de sala de aula para os cursos jurídicos que promova, ao mesmo tempo, metodologias participativas e ensino pluriversitário. Importa salientar que o modelo proposto é utilizado nas melhores faculdades de direito do mundo e seu detalhamento corresponde a aspectos de conforto e aprendizado. Para tanto será utilizado um método dedutivo, calcado em elementos doutrinários e empíricos.

Palavras-chave: Metodologias ativas; Estruturas físicas; Conhecimento pluriversitário. 
ABSTRACT: The aim of this paper to analyze how the physical structure traditionally made available for classes in Law Courses can be modified to allow a more dynamic and efficient learning, concerned with the full training of students and the production of a multidisciplinary knowledge. Law education currently lacks informative provisions that, from the physical conception, can influence student training for practical purposes. Therefore, it is necessary to rethink our legal training model, in an aspect that goes through both the learning method, inserted in a new physical context, and through the interaction of legal disciplines with community aspects. Based on these models, we intend to present a classroom model for law courses that promotes, at the same time, participatory methodologies and multidisciplinary teaching. It should be noted that the proposed model is used in the best law schools in the world and its detailing corresponds to aspects of comfort and learning. For that, a deductive method will be used, based on doctrinal and empirical elements.

Keywords: Active methodologies; Physical structures; Pluriversity knowledge.

SUMÁRIO: Introdução. 1 A transformação do espaço físico da sala de aula. 2 As metodologias em prol da formação jurídica. $3 \mathrm{O}$ modelo de sala e a metodologia direcionada no novo ensino jurídico. 3.1 Aspectos físicos da sala de aula. 3.2 O método de trabalho e o vínculo entre o professor e a sala. Conclusão. Referências.

\section{INTRODUÇÃO}

O mundo contemporâneo é exigente. Ao mesmo tempo em que revoluciona a informação e as características dos alunos, passa a vislumbrar o professor não apenas enquanto um ser revelador, mas como alguém que precisa apresentar um diferencial para auxiliar na compreensão mundana dos discentes.

Neste sentido, a informação não é mais o diferencial entre aluno e professor, posto que pode ser obtida por aquele em fração de segundos, dispensando-se até mesmo as vetustas consultas intermináveis nos ambientes bibliotecários. O que lhes diferencia, neste novo mundo, é a capacidade do docente para administrar o interesse dos alunos e incentivar-lhes a re-conhecer o ambiente em que vivem.

No campo jurídico, a informação é difusa. Desde sites, até mesmo as revistas científicas eletrônicas, ebooks, ordenamento jurídico on-line, tudo pode ser encontrado na internet. Em um ambiente contemporâneo, cada vez menos a padronização escolar e o tempo de sala de aula importam.

Como desenvolver, na graduação jurídica, um curso que enfrente tais desafios, consubstanciado em um espaço físico favorável, no ambiente pessoal de aprendizagem e em metodologias ativas?

Nas universidades norte-americanas, sabe-se que os cursos jurídicos primam pela prática, relegando a teoria apenas ao aspecto geral e introdutório da matéria. No Brasil, contudo, temos de lidar com uma série de avaliações externas, oficiais ou não, que acabam engessando o curso, tais como Exame Nacional do Ensino Superior, Exame da Ordem dos Advogados e uma gama imensurável de concursos. No fundo, o que os alunos esperam de um curso de Direito no Brasil é que este possa lhes preparar para enfrentar tais exames.

Isto tudo é agravado pela ampla abertura conferida ao ensino superior no início dos anos 2.000, em grande parte de péssima qualidade. O Brasil soma 1.240 cursos de Direito, contra 1.100 do restante do mundo. Os Estados Unidos, que detém 10 dentre as 10 melhores faculdades de 
Direito do mundo, segundo o Center for World University Rankings (CWUR), possuem apenas 212 cursos $^{1}$.

Quanto ao ensino jurídico nos Estados Unidos, contudo, são necessárias algumas considerações, pois, ao contrário do que ocorre no Brasil, o aluno interessado em atuar na área jurídica primeiro precisa cursar o College, curso bastante generalista que, ao ser concluído, capacita o aluno para ingressar em curso específico na área jurídica, conhecido como Juris Doctor (JD), o qual é voltado para áreas específicas e visa promover a capacitação profissional do formado, buscando atender os anseios do mercado e do mundo moderno ${ }^{2}$.

Esta também deve ser a vertente a direcionar os cursos jurídicos no Brasil, pois, além da necessária qualidade, os cursos precisam demonstrar capacidade de inovação, isto é, atender a necessidade de que o aluno, a despeito das amarras externas ao curso, forme-se profissional de alto nível intelectual, apto a discorrer sobre a dogmática, mas com perfil político, filosófico, sociológico e antropológico. Mais do que meros operadores do Direito, o mercado imprescinde de profissionais que saibam desenvolver um raciocínio lógico ou interpretar um texto legal complexo.

Nesse sentido, imprescindível que o conhecimento gerado no âmbito do curso de direito não tenha como destino apenas o público interno, sem a preocupação de sua efetiva aplicação prática na sociedade, ou seja, já não é suficiente que o conhecimento gerado seja universitário, sendo necessária uma transição para um conhecimento "pluriversitário".

Para tanto, nada pode ser mais realista e fidedigno do que a junção entre o ambiente físico, a disposição discente-docente, a interação no nível de aprendizagem e a utilização de metodologias diferenciadas. Note-se que a revolução nos cursos de Direito é tão complexa que exige uma soma de fatores, como iremos demonstrar, cada qual com a sua contribuição no processo de formação. Até mesmo elementos a que se confere pouca importância, como iluminação, disposição de carteiras, formato de auditório e transparência visual podem indicar significativa melhora no processo educativo.

O que se pretende, no presente estudo, é apontar um complexo sistêmico que, justificadamente, possa conduzir a esse ganho na formação de profissionais diferenciados, com a elaboração de uma proposta de modelo que possa ser colocada em prática nos cursos de Direito e, posteriormente, por meio de sua série de dados selecionados pela instituição envolvida, possa ser realizada uma análise comparativa quanto ao incremento da educação jurídica.

Para o presente estudo, a metodologia desenvolvida é propriamente dedutiva, calcada em elementos doutrinários e estudos empíricos anteriores.

\section{A TRANSFORMAÇÃO DO ESPAÇO FÍSICO DA SALA DE AULA}

Tradicionalmente, o ambiente físico da sala de aula se estruturou de forma comum em quase todos os locais, principalmente nas escolas de ensino jurídico. À frente, o quadro, a mesa e o professor. O restante da sala é tomado pelas cadeiras enfileiradas. Metodologicamente, o professor passa horas expondo o material e escrevendo no quadro enquanto os alunos anotam.

Mais preocupante é perceber que o mesmo modelo é utilizado não apenas em outros cursos de graduação, mas desde a tenra idade dos alunos até sua formação universitária. Trata-se de uma

\footnotetext{
${ }^{1}$ BORGES DE OLIVEIRA, Emerson Ademir. “Avaliações externas em nível superior e os cursos de Direito no Brasil". Revista da Faculdade de Direito da UERJ, Rio de Janeiro, v.31, 2017, p.128.

${ }^{2}$ SERVA, Fernanda Mesquita. CALDERÓN, Adolfo Ignácio. DIAS, Jefferson Aparecido. "Doutorado profissional em Direito: tendências em universidades com melhor desempenho em rankings acadêmicos internacionais". Revista Brasileira de Pós-graduação, Brasília, v. 14, 2017.
} 
escola padrão, que aborda qualquer tema, em qualquer local, da mesma forma e exige os mesmos resultados, ignorando "que a sociedade do conhecimento é baseada em competências cognitivas, pessoais e sociais, que não se adquirem da forma convencional e que exigem proatividade, colaboração, personalização e visão empreendedora"3.

Um misto de ineficiência que o vetusto modelo faz questão de reproduzir de forma tão natural como se funcionasse sempre. Mescla a frieza do ambiente físico com a mesmice metodológica. O resultado não poderia ser outro: alunos cada vez mais repetidores de matéria e com incompreensão acerca dos fenômenos sociais.

Esse modelo de promoção do ensino acaba gerando um conhecimento universitário que, segundo Boaventura de Sousa Santos, é aquele que se destina apenas para o público interno das instituições em ensino, sem a preocupação de viabilidade de sua aplicação prática pela sociedade. Tal ensino, insuficiente na atualidade, precisa ser substituído por um ensino "pluriversitário", conceituado por Boaventura de Sousa Santos ${ }^{4}$ como

[...] um conhecimento contextual na medida em que o princípio organizador de sua produção é a aplicação que lhe pode ser dada. Como essa aplicação ocorre extramuros, a iniciativa da formulação dos problemas que se pretende resolver e a determinação de critérios da relevância destes é o resultado de uma partilha entre pesquisadores e utilizadores.

A obtenção dessa nova forma de conhecimento está cada vez mais possível de ser alcançada, pois as tecnologias, o acesso à informação e a própria formação tecnológica dos alunos, no mundo contemporâneo, não apenas abrem, como exigem um universo de possibilidades. Até mesmo a sala de aula pode ser mais atrativa, menos asfixiante, e o desenvolvimento das temáticas mais produtivo:

O ambiente físico das salas de aula e da escola como um todo também precisa ser redesenhado dentro desta nova concepção mais ativa, mais centrada no aluno. As salas de aula podem ser mais multifuncionais, que combinem facilmente atividades de grupo, de plenário e individuais. Os ambientes precisam estar conectados em redes sem fio, para uso de tecnologias móveis, o que implica em ter uma banda larga que suporte conexões simultâneas necessárias ${ }^{5}$.

Um novo modelo de sala de aula precisa estimular a maior participação dos alunos. Precisa ser agradável, ao mesmo tempo em que convida à interação e à integração. Deve combinar novas tecnologias, estimulando as novas gerações acerca do ensino, especialmente quanto ao ensino jurídico, marcado por certos padrões dogmáticos que podem cansar os alunos e promover a produção de um conhecimento que já não atende os anseios da sociedade moderna.

O ambiente físico é fator essencial na mudança do modelo educacional. Como veremos mais adiante, é imprescindível para se inverter a lógica do ensino tradicional, em que o professor transmite informações e os alunos simplesmente as recebem, como a velha ótica hierárquica do empregador-empregado.

\footnotetext{
${ }^{3}$ MORAN, José. "Novos modelos de sala de aula". Educatrix, São Paulo, n.7, 2014, p.33.

${ }^{4}$ SOUSA SANTOS, Boaventura de. A universidade no século XXI: para uma reforma democrática e emancipatória da universidade. 3. ed. São Paulo: Editora Cortez, 2011, p. 76.

${ }^{5}$ MORAN, José. "Novos modelos de sala de aula". Educatrix, São Paulo, n.7, 2014, p.34.
} 
A sala de aula precisa se apresentar como um espaço "imerso num ambiente de conforto e bem-estar", sendo necessário "melhorar o espaço escola/sala de aula, tornando-o mais acolhedor, mais humano, mais bonito; um espaço que permita a interação e em que seja agradável trabalhar"6.

Gerir o espaço de trabalho é uma tarefa que deve levar em conta a finalidade do trabalho a ser desenvolvido. Como ressaltam Teixeira e Reis, a disposição, o mobiliário, as paredes e todos os elementos físicos que compõem o meio trazem influências no processo de formação e o modelo torna-se essencial para a proposta de aprendizagem corporativa ${ }^{7}$.

María Lina Iglesias Forneiro entende que o ambiente de aprendizagem é formado por quatro dimensões: a) dimensão física - considerando o espaço físico, suas condições estruturais, mobiliário, materiais, decoração e organização; b) dimensão funcional - relaciona-se à forma de utilização do espaço, polivalência e finalidade; c) dimensão temporal - diz respeito à organização do tempo e os momentos em que os espaços serão utilizados, assim como o ritmo de utilização; d) dimensão relacional - no que toca às distintas relações que se desenvolvem em sala de aula e os modos de utilizar o espaço, suas normas, agrupamentos funcionais, participação etc ${ }^{8}$.

E explica:

Pero el ambiente no es algo estático o preexistente, y si bien todos los elementos que lo componen y que agrupamos en estas cuatro dimensiones pueden existir de forma independiente, el ambiente solo existe en la interrelación de todos ellos. Sin entidad material como el espacio físico, la existencia del ambiente se da en la medida en que los elementos que lo componen interactúan entre sí. Es por eso que cada persona lo percibe de modo distinto.

Teniendo en cuenta estas cuatro dimensiones el espacio escolar, entendido como ambiente de aprendizaje, ha de ser considerado como un elemento curricular más, con una importante fuerza formativa. Esto va a depender, entre otras cosas, del nivel de congruencia con el modelo educativo en el que nos movemos: los presupuestos teóricos que definen un determinado modelo educativo condicionan el diseño del ambiente de aprendizaje y el sentido con que se utiliza, dando lugar a que distintos modelos educativos configuren el ambiente de aprendizaje de modo diferente ${ }^{9}$.

\footnotetext{
${ }^{6}$ TEIXEIRA, Madalena Telles; REIS, Maria Filomena. “A organização do espaço em sala de aula e as suas implicações na aprendizagem cooperativa". Meta: Avaliação, Rio de Janeiro, v.4, n.11, mai./ago. 2012, p.163.

${ }^{7}$ Ibidem, p.164.

${ }^{8}$ FORNEIRO, M. L. I. “Observación y evaluación del ambiente de aprendizaje en educación infantil: dimensiones y variables a considerar”. Revista Iberoamericana de Educación, Espanha, n.47, mai./ago. 2008, p.52-54.

${ }^{9}$ Ibidem. p.54. No vernáculo: "Mas o ambiente não é algo estático ou preexistente, e embora todos os elementos que o compõem e que agrupamos nessas quatro dimensões possam existir independentemente, o ambiente só existe na inter-relação de todos eles. Sem entidade física como o espaço físico, a existência do ambiente ocorre na medida em que os elementos que o compõem interagem entre si. É por isso que cada pessoa percebe isso de forma diferente. Tendo em conta estas quatro dimensões, o espaço escolar, entendido como um ambiente de aprendizagem, deve ser considerado como mais um elemento curricular, como uma importante força formativa. Isso vai depender, entre outras coisas, do nível de congruência com o modelo educacional em que nos movemos: os pressupostos teóricos que definem um modelo educacional específico determinam o design do ambiente de aprendizagem e o sentido em que ele é usado, resultando em diferentes modelos educacionais que configuram o ambiente de aprendizagem de uma maneira diferente".
} 
Nesta seara, é evidente que a organização do espaço pode facilitar ou dificultar a interação entre os alunos e entre estes e o professor ${ }^{10}$. E, a depender do tipo de didática e de ensino que se busca produzir, pode ser uma benesse ou um malefício ao processo educativo. $\mathrm{O}$ espaço pode ser estimulante ou limitador às propostas que se perquire, alcançando a excelência da metodologia ou tornando-a inútil ${ }^{11}$.

O ensino jurídico é tipicamente discursivo. A dialética apresenta-se como um processo imanente para a construção da opinião entre os estudantes. O papel social do jurista exige que o processo de interação com a sociedade se inicie e se aprimore no seio da universidade. De outro modo, estaríamos gerando juristas tímidos e egocêntricos, despreocupados com os reflexos comunitários de sua atividade.

A inserção de um novo modelo-conjunto de instalações físicas e metodologias, nesse sentido, apresenta-se também como proposta crítica ao ensino do direito pela via do "senso comum teórico", tão criticada por nomes de expressão como Luís Alberto Warat:

A epistemologia tradicional procura resolver, idealmente, as relações conflitantes entre a teoria e a práxis jurídica, ignorando, fundamentalmente, o valor político do conhecimento na práxis. Propõe um saber que seja puro como teoria e, com isso, facilita que a dita proposta seja ideologicamente recuperada, servindo agora para que os juristas contaminem a práxis de pureza, criando a ilusão de uma atividade profissional pura. Assim, os critérios de purificação metodológica ganham um novo sentido: de uma crença vinculada a uma atividade profissional. Os juristas de ofício, apoiados na idéia de um conhecimento apolitizado, acreditam que o advogado é um manipulador das leis, descompromissados politicamente, um técnico neutro das normas. As observações que terminamos de efetuar sobre a prática jurídica, apresentada como um lugar fora do poder, serve para fazer uma observação crítica sobre os postulados metódicos da teoria Kelseniana, já que seus efeitos ideológicos e políticos não provêm, isoladamente, dos valores que Kelsen propõe para a construção de uma ciência do direito em sentido estrito, senão pelos efeitos de seu discurso como guia e representação da práxis jurídica. É o discurso kelseniano, tornado senso comum, que influi para que o jurista de ofício não seja visto como um operador das relações sociais; mas sim, como um operador técnico dos textos legais ${ }^{12}$.

O jurista moderno deve lidar com os problemas brasileiros da atualidade em um sentido mais macro do que ater suas condutas para soluções de microproblemas jurídicos que abarrotam o Judiciário e a Administração Pública. Deve ser um agente, não mero operador, disposto a cooperar, em conjunto com os demais agentes, para o alcance de soluções não apenas jurídicas, mas também sociais, econômicas e políticas. E isso só será possível substituindo a inflexão e a repetição pela reflexão e o diálogo. Uma sociedade aberta de intérpretes não se faz por meio da memorização de súmulas ou de ementas decisionais, mas sim pelo desenvolvimento da capacidade de solucionar problemas.

Nesse sentido, nas últimas décadas, têm aumento nos cursos universitários, em especial na área da Saúde, a adoção de metodologias ativas que diferem dos métodos de ensino tradicionais por atribuir aos alunos o papel de protagonistas. Dentre tais metodologias, uma das mais famosas

\footnotetext{
${ }^{10}$ FERRÃO TAVARES, C. Os Media e a aprendizagem. Lisboa: Universidade Aberta, 2000, p.33.

${ }^{11}$ ZABALZA, M. A. Didáctica da educação infantil. Rio Tinto: Edições ASA, 2001.

${ }^{12}$ WARAT, Luís Alberto. "Saber crítico e senso comum teórico dos juristas”. Sequência, Florianópolis, v.3, n.5, 1982, p.52-53.
} 
é o PBL (Problem-based learning), ou seja, a aprendizagem baseada em problemas. Também se destaca a MP (Metodologia da Problematização), a qual se baseia na solução de problemas, mas se preocupa, também, em “... formar profissionais que se percebam como cidadãos participativos em uma sociedade democrática, tenham compreensão crítica da realidade e estejam dispostos a transformá-la" ${ }^{13}$, sendo que as duas metodologias se "... distinguem dos métodos tradicionais de ensino, sendo o principal deles a ênfase na aprendizagem ativa do aluno a partir da solução de problemas"14.

Um dado importante para a utilização de tais metodologias é a disposição física dos alunos em relação ao professor. Não existe um modelo correto de organização da sala, mas modelos distintos, cuja escolha dependerá do tipo de ensino que se pretende produzir.

No ensino jurídico, o debate é mola propulsora do desenvolvimento intelectual, visto como "um procedimento ou uma estratégia de ensino específico que pode ser utilizado por si só ou com uma série de modelos distintos" $" 15$. A organização, tendo esta diretriz, deve ser aquela capaz de proporcionar o melhor resultado qualitativo em termos de dialética. "Assim sendo, a disposição das carteiras em $U$ e em círculo constituem a melhor formação para as discussões, pois permitem que os alunos se vejam uns aos outros, condição fundamental para a interação verbal" 16 .

A chamada "disposição em U" mantém o professor enquanto agente incentivador do debate, sem retirar-lhe tal papel. Mas atribui características protagonistas também aos alunos, que estarão hábeis ao processo de inter-relacionamento constante, a partir das direções conferidas pelo professor $^{17}$. Este, por sua vez, poderá, sem prejuízo visual, estabelecer contato com qualquer aluno na sala, ainda mais se o ambiente se estruturar em formato de auditório.

Além disso, ao estimular uma participação contínua nos debates fomentados pelo professor, o modelo afasta condutas desviantes, seja porque a maioria estará inclinada à participação do debate, seja porque a exposição física frontal inibe tais práticas. E a atenção que, num primeiro momento, pode decorrer de tal inibição, em um segundo pode convidar à participação antes inexistente.

A disposição em "U" tem possibilitado tanto atividades em grupos (grandes e pequenos) como atividades individualizadas. Ao mesmo tempo, essa disposição facilita a circulação do professor e o contato direto com cada estudante sempre que necessário, além de proporcionar melhor gestão da classe em termos de acompanhamento do processo de ensino-aprendizagem e de organização disciplinar. Com base na prática educativa, pode-se afirmar que é o formato ideal para o modelo de ensino e avaliação por competência ${ }^{18}$.

\footnotetext{
${ }^{13}$ FREITAS, Raquel Aparecida Marra da Madeira. Ensino por problemas: uma abordagem para o desenvolvimento do aluno. Educação e Pesquisa, São Paulo, v. 38, n. 2, p. 403-418, abr./jun. 2012, p. 408.

${ }^{14}$ FREITAS, Raquel Aparecida Marra da Madeira. Ensino por problemas: uma abordagem para o desenvolvimento do aluno. Educação e Pesquisa, São Paulo, v. 38, n. 2, p. 403-418, abr./jun. 2012, p. 405.

${ }^{15}$ ARENDS, R. I. Aprender a ensinar. 7.ed. Lisboa: McGraw-Hill, 2008, p.412.

16 TEIXEIRA, Madalena Telles; REIS, Maria Filomena. "A organização do espaço em sala de aula e as suas implicações na aprendizagem cooperativa". Meta: Avaliação, Rio de Janeiro, v.4, n.11, mai./ago. 2012, p.175-176.

17 "O centro de atenção já não é o que há no quadro-negro, mas o que está acontecendo no campo dos alunos. Este simples deslocamento põe em dúvida muitas das formas habituais de se relacionar em classe, mas questiona consideravelmente o cenário". ZABALA, Antoni. A prática educativa. Porto Alegre: Artmed, 1998. p.131-132.

${ }^{18}$ MUNSBERG, João Alberto Steffen; FELICETTI, Vera Lucia. "A sala de aula como espaço de formação mútua dos sujeitos". $6^{\circ}$ Encontro Internacional da Sociedade Brasileira de Educação Comparada; 17-20 set. 2014; Bento Gonçalves. Campinas: SBEC, 2014, p.4.
} 
A sistemática adotada, como iremos ver no próximo tópico, permite a conversão do ensino tradicional em "aprendizagem cooperativa", que estimule, por exemplo, a interdependência, a liderança e a responsabilidade mútua, objetivos fulcrais do ensino jurídico, bem como a substituição do conhecimento gerado de universitário para pluriversitário.

Com base em tais afirmações, propomos uma avaliação sobre os modelos de sala utilizados nas cinco melhores faculdades de Direito do mundo, de acordo com o CWUR: Harvard University, University of Chicago, New York University, Yale University e Columbia University, conforme fotos extraídas dos sites oficiais dos cursos.

Embora não seja utilizado em todas as salas de aula de cada curso, o modelo proposto é adotado em todos os cursos acima indicados. Vejamos, a título de exemplo, as salas de aula de Yale e Harvard:

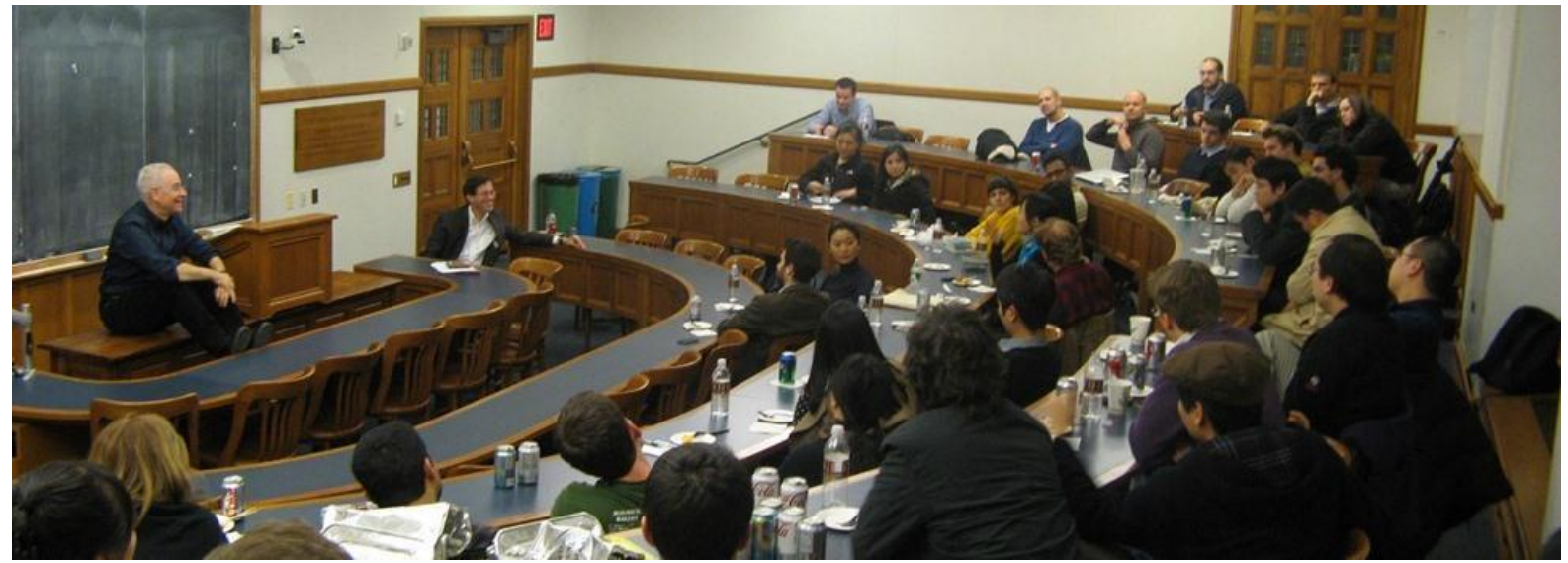

Fig.1. Yale Law School

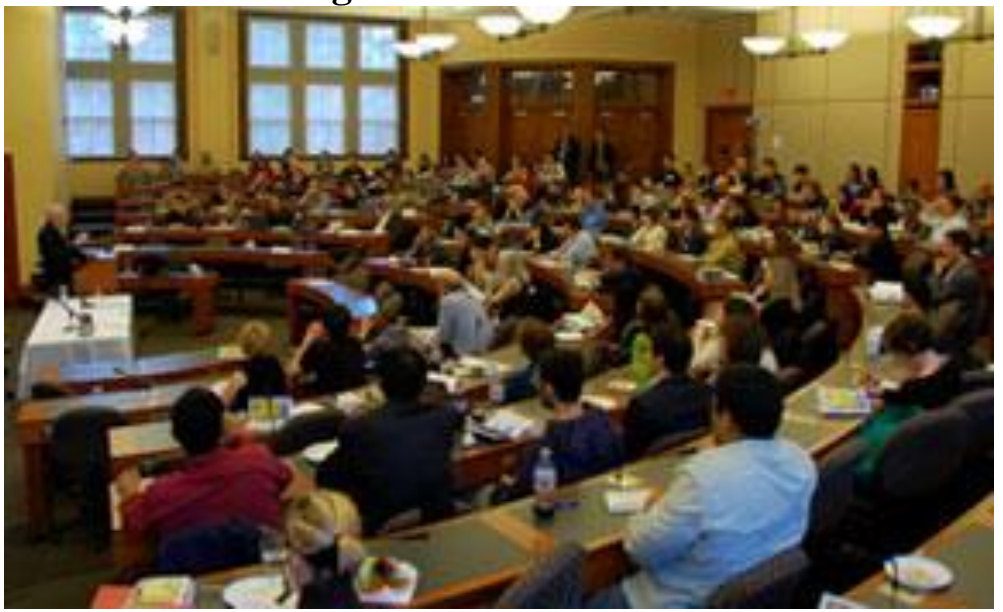

Fig.2. Harvard Law School

Com base nos aspectos fundamentais acima apresentados, discorreremos no tópico 4 acerca de um modelo físico de sala de aula a ser adotado para os cursos de Direito, com o fim de atingir os objetivos solidificados com a aprendizagem cooperativa e a produção de conhecimento pluriversitário. 


\section{AS METODOLOGIAS EM PROL DA FORMAÇÃO JURÍDICA}

O ensino jurídico atual é estigmatizante. Mais do que se preocupar com a qualidade do ensino e a formação humanística e social do jurista, volta-se para o enxerto de um altíssimo número de matérias na mente do aluno, de modo a prepará-lo para exigências mercadológicas que podem ser consideradas ultrapassadas.

As aulas no curso de Direito são praticamente todas expositivas, sem vivência interativa e com pouca inversão didática. As exigências posteriores ao curso, como já indicadas, praticamente obrigam a este formato de ensino. Para muitos, no Brasil atual, melhor curso é aquele que possui maior média de aprovação no Exame de Ordem. E este, infelizmente, é um padrão que norteia a escolha dos ingressantes. O mesmo serve para aprovação em concursos públicos, bem como para o Exame Nacional de Desempenho de Estudantes (ENADE), aplicado pelo INEP (Instituto Nacional de Estudos e Pesquisas Educacionais Anísio Teixeira).

Isto conduz a um tipo de ensino quase totalmente dogmático e pouquíssimo crítico. O bacharel em Direito pouco sabe sobre o seu papel social. Ao passar no Exame de Ordem considerase apto a exercer a função pelo resto da vida.

Mesmo as matérias de formação humanística não são desenvolvidas a contento. Em vista das exigências ulteriores que já mencionamos, acabam inseridas no início do curso, quando o aluno ainda não pode fazer a ligação entre a importância de tais matérias e a compreensão do Direito. $O$ resultado: os cursos de Direito vivem hoje em função da aprovação de seus egressos em exames e concursos públicos.

Claro que não argumentamos contra a exigência dos referidos exames, eis que eles pelo menos podem exigir melhor formação conteudista dos candidatos para que os novos advogados tenham ao menos conhecimento teórico na defesa dos direitos alheios. Logo, a inclinação para o conteúdo material ainda continuará, até que a Ordem dos Advogados e o INEP possam pensar em modelos mais elaborados de avaliação.

Isso não impede, todavia, de se desenvolver uma metodologia diferenciada no ensino do direito, de forma que exista uma formação mais interativa e um papel mais substancial por parte dos alunos, hoje sujeitos completamente passivos no ensino.

Noutras palavras, o conteúdo material não é esquecido, mas é desenvolvido a partir de um formato diferente que incentive os alunos à pesquisa e à interação do direito com outros ramos, como a política, a economia e as ciências da sociedade. Além disso, busca formar um jurista mais participativo, pronto ao embate, acadêmico ou jurídico, capaz de dialogar e debater acerca dos interesses que defende. Diga-se: um jurista mais completo.

A título de exemplo, muitos docentes, nos dias atuais, preocupam-se com o uso do celular em sala de aula. Para a maioria, a Universidade sempre faz bem ao bani-los. Ocorre que celulares, tablets e notebooks, quando bem utilizados, apresentam-se como ferramentas de extrema utilidade no ensino jurídico. Permitem, por exemplo, o acesso instantâneo a leis, súmulas, decisões judiciais e ensaios jurídicos, enriquecendo a discussão acadêmica. No modelo que apresentamos, essas ferramentas são consideradas para um desenvolvimento mais interativo. $\mathrm{O}$ mais fascinante da tecnologia é que ela amplia infinitamente os espaços físicos.

O professor pode, por exemplo, elaborar perguntas por meio de aplicativo ou site, de forma a avaliar os alunos após a discussão teórica sobre o tema. Ou pedir-lhes para assistir um vídeo ou ler uma decisão jurisprudencial.

É claro que não existe revolução no ensino jurídico se os professores não mudarem também a sua forma de ensinar. Este modelo proporciona aquilo que José Moran, professor da USP, chama de "aula invertida": 
Os ajustes necessários - mesmo progressivos - são profundos, porque são do foco: aluno ativo e não passivo, envolvimento profundo e não burocrático, professor orientador e não transmissor.

No modelo disciplinar, precisamos "dar menos aulas" e colocar o conteúdo fundamental na WEB, elaborar alguns roteiros de aula em que os alunos leiam antes os materiais básicos e realizem atividades mais ricas em sala de aula com a supervisão dos professores. Misturando vídeos e materiais nos ambientes virtuais com atividades de aprofundamento nos espaços físicos (salas) ampliamos o conceito de sala de aula: Invertemos a lógica tradicional de que o professor ensine antes na aula e o aluno tente aplicar depois em casa o que aprendeu em aula, para que, primeiro, o aluno caminhe sozinho (vídeos, leituras, atividades) e depois em sala de aula desenvolva os conhecimentos que ainda precisa no contato com os colegas e com a orientação do professor ou professores mais experientes

(...)

Um dos modelos mais interessantes de ensinar hoje é o de concentrar no ambiente virtual o que é informação básica e deixar para a sala de aula as atividades mais criativas e supervisionadas. É o que se chama de aula invertida. A combinação de aprendizagem por desafios, problemas reais, jogos, com a aula invertida é muito importante para que os alunos aprendam fazendo, aprendam juntos e aprendam, também, no seu próprio ritmo. Os jogos e as aulas roteirizadas com a linguagem de jogos cada vez estão mais presentes no cotidiano escolar. Para gerações acostumadas a jogar, a de desafios, recompensar, de competição e cooperação é atraente e fácil de perceber ${ }^{19}$.

Além disso, o modelo proposto, a partir do ajuste físico necessário, auxilia naquilo que se pode compreender como "aprendizagem cooperativa". Na aprendizagem cooperativa, os alunos são incentivados a resolver problemas em conjunto, seja por meio do debate amplo, seja por meio do debate em grupo, por meio de "estruturas de tarefas, de objetivos e recompensas", e também mediante esforço conjunto para alcançar o mesmo objetivo ${ }^{20}$.

Como continuam os autores, o grupo sob o modelo de aprendizagem cooperativa demonstrará uma série de fatores diferenciados, como a interdependência positiva, a responsabilidade individual e, ao mesmo tempo, mútua partilhada, o compartilhamento da liderança, heterogeneidade, a ênfase na tarefa, o papel estimulador do professor e a produtividade do grupo como um todo ${ }^{21}$. Tudo isso se conforma em um sistema de resultados que qualifica o desempenho escolar, aumenta a tolerância e a aceitação da diversidade e incrementa as competências sociais ${ }^{22}$.

Arends resume:

Os alunos trabalham em equipe para atingirem os objetivos de aprendizagem.

As equipes são constituídas por alunas de um rendimento elevado, médio e fraco.

Sempre que possível, as equipas incluem uma mistura de raças, de culturas e de género.

\footnotetext{
${ }^{19}$ MORAN, José. "Novos modelos de sala de aula”. Educatrix, São Paulo, n.7, 2014, p.35-36.

20 TEIXEIRA, Madalena Telles; REIS, Maria Filomena. "A organização do espaço em sala de aula e as suas implicações na aprendizagem cooperativa”. Meta: Avaliação, Rio de Janeiro, v.4, n.11, mai./ago. 2012, p.180.

${ }^{21}$ Ibidem. p.181.

${ }^{22}$ Ibidem. p. 182.
} 
Os sistemas de recompensa são orientados para o grupo assim como para o indivíduo ${ }^{23}$.

O funcionamento deste sistema de maior interação acaba por desenvolver um leque elevado de competências que deveriam ser inerentes a todo profissional jurista: "A autonomia profissional implica diálogo, compreensão, negociação, intermediação, mediação e equilíbrio" 24 .

Vê-se, assim, que o estabelecimento de uma ação pedagógica mais direcionada, com metodologia que estimule o funcionamento em grupo, a interação, a interatividade e o uso das ferramentas tecnológicas, pode gerar as competências necessárias aos juristas, sem olvidar dos desafios requeridos pelos exames posteriores mencionados.

Diferentemente dos Estados Unidos, o direito brasileiro ergueu-se sob uma vertente muito mais escrita do que oral, razão pela qual demoramos a nos preocupar com tais atividades formativas. Hoje, no entanto, a despeito da limitação ao uso do Tribunal do Júri, a oralidade começa a tomar conta de todo tipo de procedimento, assim como a competência para dialogar e resolver os conflitos nas formas autocompositivas e heterocompositivas. É preciso que o profissional do direito tenha formação social e psicológica, saiba discutir valores, princípios, e não apenas o direito. Saiba incentivar seu cliente não apenas a perquirir seu direito acima de tudo, mas a ceder quando isso for viável e mais prático, isto é, quando os ganhos, envolvendo todos os aspectos, forem maiores em um longo prazo.

Ocorre que nada disso se constrói no exercício meramente expositivo do direito. Não são lições que possam ser retiradas do modelo físico de sala de aula com carteiras enfileiradas, em que os últimos perdem grande parte da atenção e conteúdo, e o professor passa horas repetindo aquilo que poderia ser apreendido mediante leitura e estudo.

Também a dogmática pura e simples não conduz à crítica. $\mathrm{O}$ aluno não é estimulado a debater, mas a entender e repetir. Não lhe cabe questionar as razões pelas quais as leis foram feitas, mas armazená-las porque o tipo de cobrança que lhe será direcionado será meramente de conteúdo.

Estamos em um ponto fulcral do ensino jurídico. Ou mudamos a forma de ensinar o Direito ou, em breve, o profissional poderá ser substituído por qualquer computador que, em tempo muito menor, já é capaz de identificar processos, peças, teses e possibilidade de ganho, por meio de softwares extremamente bem elaborados e treinados, veja-se, pelos próprios juristas. Em breve, será capaz de até mesmo elaborar defesas e recursos ${ }^{25}$.

\section{O MODELO DA SALA E A METODOLOGIA DIRECIONADA NO NOVO ENSINO JURÍDICO}

Apresentadas as bases teóricas acerca do espaço físico e da metodologia de ensino, passamos a dialogar acerca desta necessária união para uma melhoria do ensino jurídico e elaboração de um modelo tido como de excelência para o ensino jurídico, tanto no que diz respeito ao espaço físico, quanto no que toca aos aspectos metodológicos. A partir da adoção de tal modelo pelos cursos de Direito, o que se espera é que os resultados, nos locais que vierem a adotar tal modelo, tragam maior conhecimento teórico, prático e humanístico dos alunos.

\footnotetext{
${ }^{23}$ ARENDS, R. I. Aprender a ensinar. 7.ed. Lisboa: McGraw-Hill, 2008, p.345.

${ }^{24}$ MUNSBERG, João Alberto Steffen; FELICETTI, Vera Lucia. "A sala de aula como espaço de formação mútua dos sujeitos". $6^{\circ}$ Encontro Internacional da Sociedade Brasileira de Educação Comparada; 17-20 set. 2014; Bento Gonçalves. Campinas: SBEC, 2014, p.6.

${ }^{25}$ MANDALITI, Renato. "A disrupção do Jurídico com uso da Inteligência artificial”. Palestra proferida na XXIV Semana Jurídica da Universidade de Marília. Marília, São Paulo. 24 ago. 2017.
} 
Passaremos, pois, a expor os detalhes físicos e metodológicos da sala de aula e do conjunto formativo, iniciando-se por aqueles.

\subsection{Aspectos físicos da sala de aula}

Será apresentada, a seguir, uma proposta de modelo a ser adotada pelos cursos de Direito. Inicialmente, vejamos o detalhamento físico do ambiente:

a) Disposição da sala em "U", no formato de auditório - conforme já discutido, o formato é o que se apresenta teoricamente mais hábil para o processo evolutivo dialético do estudante de Direito. E para não minorar o aprendizado das fileiras posteriores, é preciso que este modelo seja implementado no formato de auditório, conforme imagem em anexo, com um número adequado de posições, que garanta o conforme dos alunos;

b) Instrumentalização das bancadas - de forma a permitir a utilização de tecnologias, as bancadas serão equipadas com tomadas, na razão de uma tomada por assento;

c) Conforto ambiental - a transmissão da sensação de conforto ao aluno, permitindo-lhe maior desenvoltura, é essencial. Para tanto, a sala deverá ser equipada com paredes claras, carpete, iluminação em "U" sobre as bancadas e ar condicionado;

d) Instrumentalização da sala - de forma a propiciar maior utilização da tecnologia a serviço do ensino, a sala

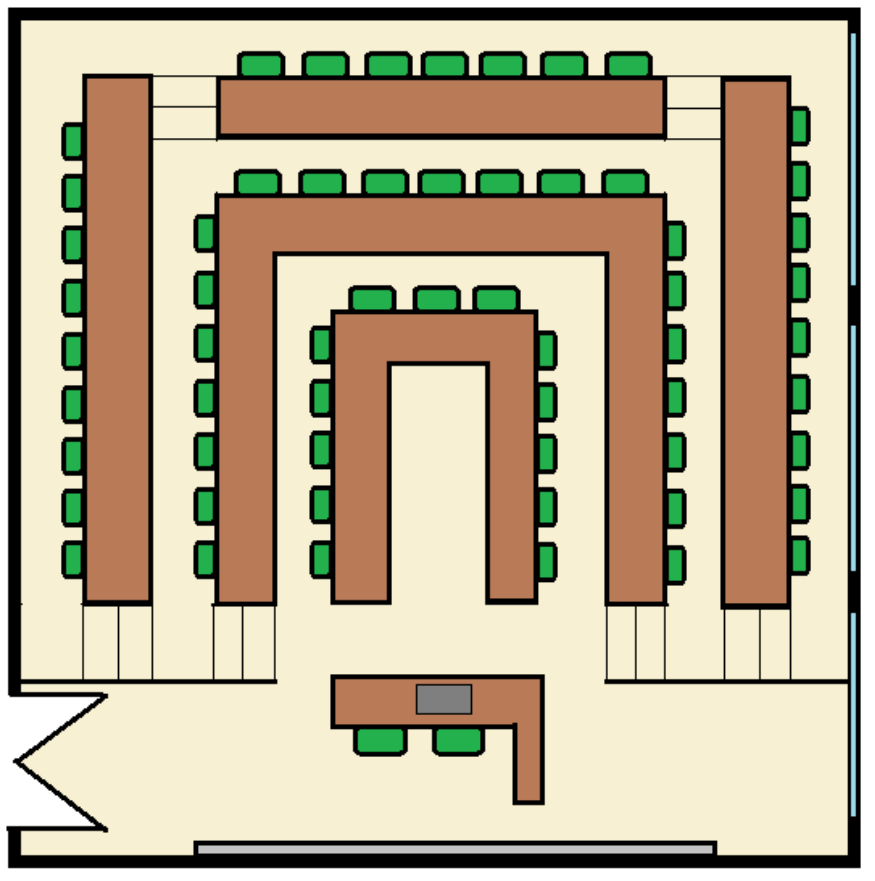
será equipada com sistema de internet wi-fi, sistema de som com microfone sem fio, lousa moderna e, na bancada do professor, computador conectado a projetor na parede da lousa e pequena estante de livros de consulta na lateral;

e) Acessibilidade e transparência - no intuito de atender melhor a pessoas portadoras de limitações físicas, além da primeira bancada térrea, a porta passa a ser dupla, com 60 centímetros para cada parte, com abertura interna e sistema de fechamento automático, além de barras horizontais para abertura. Além disso, como forma a permitir transparência, as portas serão dotadas de vidro, em retângulos de 50 centímetros por 40 centímetros, a iniciar na altura de 1,50 metro.

\subsection{O método de trabalho e o vínculo entre o professor e a sala}

Como igualmente antecipado, a metodologia inerente a tal sistema exige maior proatividade dos alunos e um papel mais intermediador do professor. De pouco adianta um novo mobiliário a reformulação do espaço físico se não for acompanhada por uma nova mentalidade de 
ensino. Como afirmam Teixeira e Reis, "o uso do espaço na sala de aula, bem como do mobiliário movível, requer uma atenção especial numa aula de aprendizagem coletiva"26.

O espaço físico é um fator extremamente importante na didática, mas não se confunde com a própria didática.

Conforme antecipado, os aspectos físicos devem contribuir para o desenvolvimento da interação de ensino e da aprendizagem cooperativa. Assim, por exemplo, o sistema multimídia, a internet sem fio e a disposição de tomadas. É preciso que as tecnologias sejam direcionadas em prol de uma formação jurídica qualitativa.

Logo, ao mesmo tempo em que se requer mudanças estruturais no ambiente, requer-se também mudanças na didática de ensino dos professores. O professor deve estar hábil ao modelo invertido, que possibilita ao aluno um preparo anterior à aula e discussões aprofundadas em substituição ao modelo meramente expositivo.

Outro fator de relevo é o vínculo a ser criado entre o professor e o ambiente físico, tornando-lhe familiar e propiciando um desenvolvimento acadêmico mais íntimo. $\mathrm{O}$ espaço da sala de aula deixa de ser puramente um local de trabalho, passando a ser agradável tanto aos discentes quanto aos docentes.

Além disso, conforme já mencionado, ao lado da mesa do professor, disponibiliza-se uma bancada para o armazenamento de livros para consulta pelo docente e pelos alunos. A criação de um vínculo do docente com a sala, ainda, propicia um ponto de apoio do próprio docente, onde ele poderá ser encontrado para orientação e pesquisa. Mais do que isso, trata-se de local em que o docente desenvolverá suas atividades científicas, vinculando-o à instituição em lapso temporal maior, sempre respeitada a legislação trabalhista. Assim, além do ganho na formação dos alunos, há um ganho para o próprio professor e para a Instituição de Ensino.

Inicialmente, a Instituição de Ensino pode adotar um projeto-piloto, que envolva apenas uma sala de aula, com vinculação de alguns professores, de forma a se medir a relação entre o professor e a sala. O ideal, contudo, é que cada docente disponha de sua própria sala de aula.

Como todo método teórico, o empirismo se faz necessário para que a evolução ou involução da implementação possa ser medida. Nesse ponto, é imprescindível para a análise acerca do conjunto que envolve o ambiente físico e o método e a necessidade de mudanças e/ou adequações.

A fim de se avaliar a desenvoltura acadêmica no novo modelo, duas sugestões de avaliação podem ser resumidas nas seguintes concepções: a) a análise da evolução das notas de uma matéria parcial de uma mesma turma que tenha frequentado a mesma sala, antes e depois ${ }^{27}$; b) a análise da evolução das notas em uma determinada disciplina que tenha sido ministrada fora desse ambiente e, agora, neste novo ambiente ${ }^{28}$.

Tal análise permite dois tipos de comparação: a) a evolução de uma mesma turma, antes e depois do ambiente e do método; b) a evolução de turma distintas, na mesma matéria, antes e depois do ambiente e do método.

\footnotetext{
26 TEIXEIRA, Madalena Telles; REIS, Maria Filomena. "A organização do espaço em sala de aula e as suas implicações na aprendizagem cooperativa”. Meta: Avaliação, Rio de Janeiro, v.4, n.11, mai./ago. 2012, p.183.

${ }^{27}$ A ideia corresponde a uma avaliação de matéria composta de mais de um segmento, como, por exemplo, Direito Constitucional I, II e III. Busca-se comparar, por exemplo, as médias obtidas em Direito Constitucional I, em outro ambiente e sob outra metodologia, e em Direito Constitucional II, já sob o novo enfoque.

28 Neste ponto, olha-se unicamente para uma determinada disciplina e analisa-se a média da turma anterior, desenvolvida em outro ambiente e sob outra metodologia, em comparação com a turma atual, em novo ambiente e sob nova metodologia.
} 
A medição empírica, contudo, deve ser desenvolvida e avaliada por cada Instituição, de forma a atender suas necessidades.

\section{CONCLUSÃO}

O ensino jurídico, como todo ensino desenvolvido pelas Universidades e demais instituições de ensino, passa por um momento de crise, na qual o conhecimento gerado, aparentemente, já não é apto a ser aplicado na prática pela sociedade.

No caso do Brasil, essa crise no ensino jurídico ainda foi agravada pela proliferação desenfreada de novos cursos de Direito, o que fez com que o país concentrasse mais cursos de Direito que todo o globo terrestre.

Por outro lado, o estabelecimento de parâmetros a partir da necessidade de aprovação ou bom desempenho dos egressos em certos exames tem feito com que o conhecimento gerado possa ser classificado como universitário, o qual, segundo Boaventura de Sousa Santos, é aquele conhecimento destinado ao consumo do público interno das instituições de ensino, sem a preocupação de sua aplicação extramuros, na sociedade.

Assim, nos dias de hoje, os cursos de Direito preocupam-se muito mais com o índice de aprovação em Exames de Ordem, concursos e avaliação no ENADE do que propriamente com o aprofundamento das matérias lecionadas e o desenvolvimento de um pensamento crítico e capacidade intuitiva de resolução de situações-problema por parte do aluno. O resultado disso, muitas vezes, é a geração de alunos teóricos desvinculados da prática.

Segundo Boaventura, é imprescindível que esse conhecimento universitário seja substituído por um conhecimento pluriversitário, desenvolvido de forma contextualizada com o ambiente no qual está sendo produzido, a partir da utilidade prática que lhe pode ser dada e da relação que deve existir entre pesquisadores e utilizadores. Esse conhecimento, de acordo com o presente trabalho, pode ser facilitado a partir de um processo de aprendizagem cooperativa.

Para tanto, o modelo tradicional do ensino jurídico deve ser aperfeiçoado e tal processo passa pela adoção de um novo espaço físico para a realização da relação de ensino e aprendizagem, conforme proposta de modelo aqui apresentada.

O novo ambiente físico deve estimular a interação entre os próprios alunos e entre os alunos e os professores, além de estar adaptado às novas tecnologias que não podem ser simplesmente expulsas da sala de aula. Ao contrário, devem ser tomadas como grandes aliadas no processo educacional da era da informação.

Por outra via, e até para fazer frente a essas novas confecções, uma nova metodologia deve ser adotada, pois a metodologia tradicional, baseada quase que exclusivamente em aulas expositivas, deve ser substituída por um novo modelo calcado em metodologias ativas. $\mathrm{O}$ uso das tecnologias atuais, por exemplo, auxilia na interação dos alunos com as disciplinas ministradas, podendo convidá-los a uma rede de descobertas e pesquisas infindável.

Um ensino jurídico, assim, que nem se furte às necessidades que todos os cursos mantêm por razões externas, e que, infelizmente, não estão na raia de controle das faculdades, mas que, ao mesmo tempo, forme mais do que burocratas do Direito, eivados sob uma lógica meramente expositiva e desvinculada da realidade social. 


\section{REFERÊNCIAS}

ARENDS, R. I. Aprender a ensinar. 7.ed. Lisboa: McGraw-Hill, 2008.

BORGES DE OLIVEIRA, Emerson Ademir. Avaliações externas em nível superior e os cursos de Direito no Brasil. Revista da Faculdade de Direito da UERJ, Rio de Janeiro, v.31, 2017, pp.127-143.

FERRÃO TAVARES, C. Os Media e a aprendizagem. Lisboa: Universidade Aberta, 2000.

FORNEIRO, M. L. I. Observación y evaluación del ambiente de aprendizaje en educación infantil: dimensiones y variables a considerar. Revista Iberoamericana de Educación, Espanha, n.47, mai./ago. 2008, pp.49-70.

FREITAS, Raquel Aparecida Marra da Madeira. Ensino por problemas: uma abordagem para o desenvolvimento do aluno. Educação e Pesquisa, São Paulo, v. 38, n. 2, p. 403-418, abr./jun. 2012.

MANDALITI, Renato. A disrupção do Jurídico com uso da Inteligência artificial. Palestra proferida na XXIV Semana Jurídica da Universidade de Marília. Marília, São Paulo. 24 ago. 2017.

MORAN, José. Novos modelos de sala de aula. Educatrix, São Paulo, n.7, 2014, pp.33-37.

MUNSBERG, João Alberto Steffen; FELICETTI, Vera Lucia. A sala de aula como espaço de formação mútua dos sujeitos. $6^{\circ}$ Encontro Internacional da Sociedade Brasileira de Educação Comparada; 17-20 set. 2014; Bento Gonçalves. Campinas: SBEC, 2014.

SERVA, Fernanda Mesquita. CALDERÓN, Adolfo Ignácio. DIAS, Jefferson Aparecido. Doutorado profissional em Direito: tendências em universidades com melhor desempenho em rankings acadêmicos internacionais. Revista Brasileira de Pós-graduação, Brasília, v. 14, 2017.

SOUSA SANTOS, Boaventura de. A universidade no século XXI: para uma reforma democrática e emancipatória da universidade. 3. ed. São Paulo: Editora Cortez, 2011.

TEIXEIRA, Madalena Telles; REIS, Maria Filomena. A organização do espaço em sala de aula e as suas implicações na aprendizagem cooperativa. Meta: Avaliação, Rio de Janeiro, v.4, n.11, mai./ago. 2012, pp.162-187.

ZABALA, Antoni. A prática educativa: como ensinar. Porto Alegre: Artmed, 1998.

ZABALZA, M. A. Didáctica da educação infantil. Rio Tinto: Edições ASA, 2001.

WARAT, Luís Alberto. Saber crítico e senso comum teórico dos juristas. Sequência, Florianópolis, v.3, n.5, 1982, pp.48-57. 